\title{
Construction of a $\mathrm{CaHPO}_{4}$-PGUS1 hybrid nanoflower through protein-inorganic self-assembly, and its application in glycyrrhetinic acid 3-0-mono- $\beta$-D-glucuronide preparation
}

\author{
Tian Jiang", Yuhui Hou*, Tengjiang Zhang, Xudong Feng (凶), Chun Li (ه) \\ Institute for Synthetic Biosystem/Department of Biochemical Engineering, \\ School of Chemistry and Chemical Engineering, Beijing Institute of Technology, Beijing 100081, China
}

(C) Higher Education Press and Springer-Verlag GmbH Germany, part of Springer Nature 2019

\begin{abstract}
Glycyrrhetinic acid 3- $O$-mono- $\beta$-D-glucuronide (GAMG), an important pharmaceutical intermediate and functional sweetener, has broad applications in the food and medical industries. A green and cost-effective method for its preparation is highly desired. Using sitedirected mutagenesis, we previously obtained a variant of $\beta$-glucuronidase from Aspergillus oryzae Li-3 (PGUS1), which can specifically transform glycyrrhizin (GL) into GAMG. In this study, a facile method was established to prepare a $\mathrm{CaHPO}_{4}$-PGUS1 hybrid nanoflower for enzyme immobilization, based on protein-inorganic hybrid selfassembly. Under optimal conditions, $1.2 \mathrm{mg}$ of a $\mathrm{CaHPO}_{4}{ }^{-}$ PGUS1 hybrid nanoflower precipitate with $71.2 \%$ immobilization efficiency, $35.60 \mathrm{mg} \cdot \mathrm{g}^{-1}$ loading capacity, and $118 \%$ relative activity was obtained. Confocal laser scanning microscope and scanning electron microscope results showed that the enzyme was encapsulated in the $\mathrm{CaHPO}_{4}$-PGUS1 hybrid nanoflower. Moreover, the thermostability of the $\mathrm{CaHPO}_{4}$-PGUS1 hybrid nanoflower at $55^{\circ} \mathrm{C}$ was improved, and its half-life increased by 1.3 folds. Additionally, the $\mathrm{CaHPO}_{4}$-PGUS1 hybrid nanoflower was used for the preparation of GAMG through GL hydrolysis, with the conversion rate of $92 \%$ in $8 \mathrm{~h}$, and after eight consecutive runs, it had $60 \%$ of its original activity.
\end{abstract}

Keywords $\beta$-glucuronidase, enzyme-inorganic hybrid nanoflower, biotransformation, glycyrrhizin, glycyrrtinic acid 3-O-mono- $\beta$-D-glucuronide

Received January 6, 2018; accepted February 24, 2019

E-mails: xd.feng@bit.edu.cn (Feng X); lichun@bit.edu.cn (Li C)

${ }^{*}$ These authors contributed equally to this work.

\section{Introduction}

Licorice, a traditional herbal medicine, is widely utilised in many industries, including the food, pharmacy, and cosmetic industries [1]. Glycyrrhizin (GL), is a typical triterpenoid saponin and the major functional component of licorice, and efficacious against inflammation, allergy, tumor, and asthma [2]. However, the low target organ bioavailability of GL, owed to its high polarity, can reportedly be efficiently solved by hydrolyzing one of its glucuronic acid moieties, thus, yielding the derivative glycyrrhetinic acid 3-O-mono- $\beta$-D-glucuronide (GAMG). Additionally, GAMG is approximately 940 folds sweeter than sucrose, and more than 4 folds sweeter than GL, which prompts its future application as a functional natural sweetener with low-calories [3]. Biocatalysis holds the most promise for performing this transformation because of its rigorous substrate specificity [4]. $\beta$-Glucuronidase, which hydrolyzes the glucuronic bond from its nonreducing end to release glucuronic acid and aglycone moieties, has recently become popular for glucuronide conjugate modification. At present, a few $\beta$-glucuronidases that can specifically transform GL into GAMG have been reported. However, their industrial application has been limited by the difficulty of their large scale preparation and their low activity [5-7]. Our lab has previously identified 3 fungal $\beta$-glucuronidases from Aspergillus oryzae Li-3 (PGUS), Aspergillus terreus Li-20, and Aspergillus ustus Li-62, which showed high activity and poor substrate specificity in the transformation of GL to glycyrrhetinic acid (GA) [8]. Recently, we uncovered the substrate recognition mechanism of PGUS by solving its crystal structure in the intermediate GAMG complex, and obtained the PGUS variant A365H/R563E (PGUS1) by rational site-directed mutagenesis [9,10]. PGUS1 had rigorous substrate specificity towards GL, with GAMG 
as the main product, and can be produced in large-scale by heterologous expression in E. coli. These properties make PGUS1 an ideal biocatalyst for the industrial preparation of GAMG through GL hydrolysis.

Immobilization has become an efficient technology for overcoming the drawbacks of free enzyme in real applications, including instability under harsh conditions and low reusability [11-13]. High immobilization yields can be obtained in immobilization by physical methods such as absorption and encapsulation, but the immobilization is usually unstable and associated with enzyme leakage during the reaction [14]. Immobilization by chemical methods such as cross-linking and covalent binding can yield a very strongly bounded enzyme with high reusability [15], but is relatively complicated and the chemical reactions usually cause decreased enzyme activity. A facile preparation of enzyme-inorganic hybrid nanoflower has recently been proposed for enzyme immobilization, due to its many advantages such as high surface to volume ratio, easy preparation, low toxicity to enzymes, and high enzyme activity retention. The nanoflowers have been successfully used to prepare several enzymes such as laccase [16], carbonic anhydrase [16], lipase [17], $a$-amylase [18], and horseradish peroxidase [19], which are all relatively small proteins with molecular weights $<70 \mathrm{kDa}$. However, the applicability of this method to larger multimonomeric proteins with larger molecular weights needs further investigation. PGUS1 is an ideal model enzyme since it is a homotetramer with a molecular weight of $290 \mathrm{kDa}$.

In this study, a $\mathrm{CaHPO}_{4}$-PGUS1 hybrid nanoflower was constructed and systematically optimized. Then, the $\mathrm{CaHPO}_{4}$-PGUS1 hybrid nanoflower was characterized using a confocal laser scanning microscope (CLSM) and scanning electron microscope (SEM), and successfully applied in the preparation of GAMG through GL hydrolysis.

\section{Materials and methods}

\subsection{Materials}

The recombinant $E$. coli bearing the PGUS1 gene (E. coli
BL21(DE3)/pET-28a(+)-pgus1) was previously constructed in our lab [9]. Ammonium glycyrrhizinate (70\%) was purchased from Xinjiang Tianshan Pharmaceutical Co. (Xinjiang, China). Glycyrrhizin and fluorescein isothiocyanate (FITC) were purchased from SigmaAldrich (San Diego, CA, USA). All other chemicals were of the highest grade available and used without further purification.

\subsection{Enzyme expression and purification}

PGUS1 was produced in Luria-Bertani medium with $50 \mu \mathrm{g} \cdot \mathrm{mL}^{-1}$ kanamycin sulfate at $37^{\circ} \mathrm{C}$. When the $\mathrm{OD}_{600}$ reached $0.6-0.8,1 \mathrm{mmol} \cdot \mathrm{L}^{-1}$ of isopropyl $\beta$-D-thiogalactoside (IPTG) was added to induce protein expression for $10 \mathrm{~h}$ at $16^{\circ} \mathrm{C}$. Then, the cells were collected by centrifugation at $6000 \mathrm{r} \cdot \mathrm{min}^{-1}$ for $15 \mathrm{~min}$, suspended in a buffer $\left(30 \mathrm{mmol} \cdot \mathrm{L}^{-1}\right.$ Tris- $\mathrm{HCl}$ containing $150 \mathrm{mmol} \cdot \mathrm{L}^{-1}$

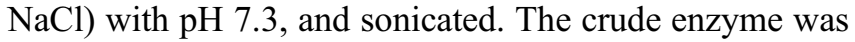
prepared by centrifugation at $12000 \mathrm{r} \cdot \mathrm{min}^{-1}$ for $20 \mathrm{~min}$, loaded onto the Ni-NTA affinity column from GE Healthcare (Beijing, China), and eluted with a buffer (30 mmol $\cdot \mathrm{L}^{-1}$ Tris- $\mathrm{HCl}$ containing $150 \mathrm{mmol} \cdot \mathrm{L}^{-1} \mathrm{NaCl}$ and $1 \mathrm{~mol} \cdot \mathrm{L}^{-1}$ imidazole) with $\mathrm{pH} 7.3$ at a $0-100 \%$ gradient. The collected enzyme was further loaded onto the HisTrap Desalting column from GE Healthcare (Beijing, China), for desalination with an elution buffer $\left(50 \mathrm{mmol} \cdot \mathrm{L}^{-1}\right.$ Tris- $\mathrm{HCl}, \mathrm{pH}$ 7.3). Enzyme purity was determined using SDS-PAGE. Enzyme concentration was measured using the Bradford method [20]. The purified enzyme was stored at $4^{\circ} \mathrm{C}$ until further use.

\subsection{Preparation of the $\mathrm{CaHPO}_{4}$-PGUS1 hybrid nanoflower}

One milliliter of calcium chloride $\left(1 \mathrm{~mol} \cdot \mathrm{L}^{-1}\right)$ and PGUS1 (pH 6.5, $0.2 \mathrm{~mol} \cdot \mathrm{L}^{-1}$ phosphate buffer) solutions were and incubated overnight. Then, post centrifugation, the precipitate was washed with deionized water until no free enzyme was detected. The enzyme loading in $\mathrm{CaHPO}_{4}{ }^{-}$ PGUS1 hybrid nanoflowers was determined by measuring the protein content of both the enzyme solution after immobilization and the washed solution, using the Bradford method. The immobilization yield was calculated using the following equation:

$$
\text { Immobilization yield }(\%)=\frac{\text { Amount of PGUS1 loaded on support }}{\text { Amount of PGUS1 totally introduced }}
$$

\subsection{Preparation of FITC-labelled PGUS1}

FITC $(5 \mathrm{~mL})$ was added to $100 \mathrm{~mL}$ of PGUS1 solution (2 $\mathrm{mg} \cdot \mathrm{mL}^{-1}$ ) and incubated for $24 \mathrm{~h}$ at $4^{\circ} \mathrm{C}$. The mixture was dialyzed in a phosphate buffer with $\mathrm{pH} 6.5$ at $4^{\circ} \mathrm{C}$ until no free FITC could be detected. The FITC-labelled PGUS1 was used to prepare the $\mathrm{CaHPO}_{4}$-PGUS1 hybrid nano- flower as described in section 2.3, and was observed using a CLSM (Leica, TSC-SP5) at an excitation wavelength of $488 \mathrm{~nm}$.

\subsection{Enzyme activity assay}

The enzyme activity was determined using GL hydrolysis. Free PGUS1 or $\mathrm{CaHPO}_{4}$-PGUS1 hybrid nanoflower was 
added to $200 \mu \mathrm{L}$ of $2 \mathrm{~g} \cdot \mathrm{L}^{-1}$ ammonium glycyrrhizinate solution ( $\mathrm{pH} 5,50 \mathrm{mmol} \cdot \mathrm{L}^{-1}$ acetate buffer), and incubated at $40^{\circ} \mathrm{C}$ for $30 \mathrm{~min}$. The reaction was stopped by adding 20 $\mu \mathrm{L}$ of $2 \mathrm{~mol} \cdot \mathrm{L}^{-1} \mathrm{NaOH}$, and then $100 \mu \mathrm{L}$ of the reactant was mixed with $900 \mu \mathrm{L}$ of methanol to prepare the sample. The sample $(10 \mu \mathrm{L})$ was injected into a C18 HPLC column
$(4.6 \times 250 \mathrm{~mm}, 5 \mu \mathrm{m}$ particle size) from Shimadzu, to quantify the reaction rate. Separation was achieved with a mobile phase consisting of a mixture of methanol and $0.6 \%$ acetic acid $(81: 19, \mathrm{v} / \mathrm{v})$ at $40^{\circ} \mathrm{C}$. The wavelength of the UV detector was set at $254 \mathrm{~nm}$. The relative activity was calculated using the following equation:

$$
\text { Relative activity }(\%)=\frac{\text { Activity of } \mathrm{CaHPO}_{4} \text {-PGUS1 hybrid nanoflower }}{\text { Activity of PGUS1 totally introduced }} \text {. }
$$

\subsection{Thermostability test}

Free PGUS1 or $\mathrm{CaHPO}_{4}$-PGUS1 hybrid nanoflower were incubated at $55^{\circ} \mathrm{C}$ and sampled at specific certain intervals. The enzyme sample was first incubated in an ice bath for $20 \mathrm{~min}$, and residual activity was evaluated using a GL hydrolysis assay as described in section 2.5. Then, the thermal deactivation kinetics of the $\mathrm{CaHPO}_{4}-\mathrm{PGUS1}$ hybrid nanoflower was investigated using first-order process [21]:

$$
E \rightarrow E^{\prime},
$$

where: $E$, active enzyme; $E^{\prime}$, deactivated enzyme; The thermal deactivation rate equation can be obtained using the following equation:

$$
\frac{\mathrm{d} A}{\mathrm{~d} t}=-k_{\mathrm{d}} A
$$

where: $A$, enzyme activity at time $t$ during the thermal deactivation process; $k_{\mathrm{d}}$, deactivation rate constant. Equation (1) can be integrated into Eq. (2) to give:

$$
\ln \left(\frac{A}{A_{0}}\right)=-k_{\mathrm{d}} t
$$

where: $A_{0}$, initial activity.

Therefore, at a given temperature, a semi natural logarithm plot of residual activity as time should give a straight line, where the negative slop is the deactivation rate constant $k_{\mathrm{d}}$.

2.7 Characterization of the $\mathrm{CaHPO}_{4}$-PGUS1 hybrid nanoflower

The SEM images of the $\mathrm{CaHPO}_{4}$-PGUS1 hybrid nanoflower were recorded using a JSM-5600LV SEM instrument (Tokyo, Japan), and its zeta potentials and particle size distribution were measured in deionized water using a Zetasizer Nano ZS from Malvern instruments (Malvern, UK).

\section{Results and discussion}

3.1 Effect of different divalent metal ions on PGUS1 activity

To construct a stable hybrid-nanoflower, a suitable divalent metal ion must be selected. The effects of different divalent metal ions, including $\mathrm{Co}^{2+}, \mathrm{Mg}^{2+}, \mathrm{Ni}^{2+}, \mathrm{Zn}^{2+}$, and $\mathrm{Ca}^{2+}$ on PGUS1 activity were investigated. The enzyme was incubated with different concentrations of 5 divalent metal ions at room temperature. As shown in Fig. 1, low concentrations of $\mathrm{Mg}^{2+}, \mathrm{Ni}^{2+}$, and $\mathrm{Ca}^{2+}$ improved PGUS1 activity, with $5-20 \mathrm{mmol} \cdot \mathrm{L}^{-1}$ of $\mathrm{Ca}^{2+}$ causing the highest relative activity of $124.5 \% . \mathrm{Ca}^{2+}$ was therefore selected as the divalent metal ion for the construction of the enzymeinorganic nanoflower.

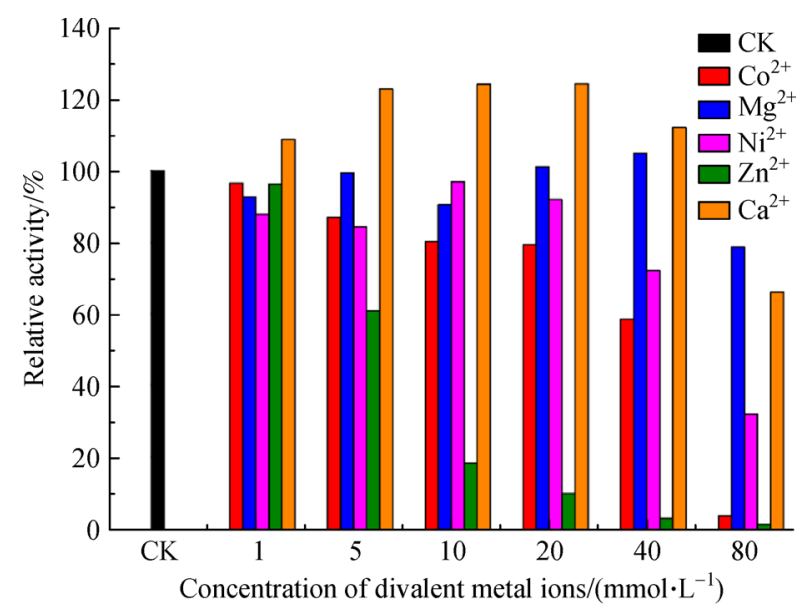

Fig. 1 Effect of divalent metal ions on the activity of PGUS1.

\subsection{Preparation of $\mathrm{CaHPO}_{4}$-PGUS1 hybrid nanoflower}

To obtain a robust $\mathrm{CaHPO}_{4}$-PGUS1 hybrid nanoflower biocatalyst, the main factors such as the concentration of $\mathrm{Ca}^{2+}$, phosphate, and enzyme, and the incubation time, were thoroughly investigated with respect to the nanoflower precipitate mass, loading capacity, and relative activity.

$\mathrm{Ca}^{2+}$ and phosphate played an important role in precipitate formation; hence, their effects were firstly investigated. As shown in Fig. 2(a), precipitate mass and loading capacity were not affected when the concentration of $\mathrm{Ca}^{2+}$ was $>2 \mathrm{mmol} \cdot \mathrm{L}^{-1}$. Nonetheless, relative activity dramatically increased as the concentration of $\mathrm{Ca}^{2+}$ increased from $0.02-0.6 \mathrm{mmol} \cdot \mathrm{L}^{-1}$, but was relatively stable when the concentration was between 0.6 and $2 \mathrm{mmol} \cdot \mathrm{L}^{-1}$. The highest relative activity of $112 \%$ was achieved with $1.6 \mathrm{mmol} \cdot \mathrm{L}^{-1}$ of $\mathrm{Ca}^{2+}$. However, when the 


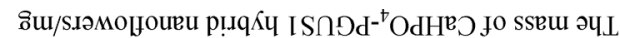

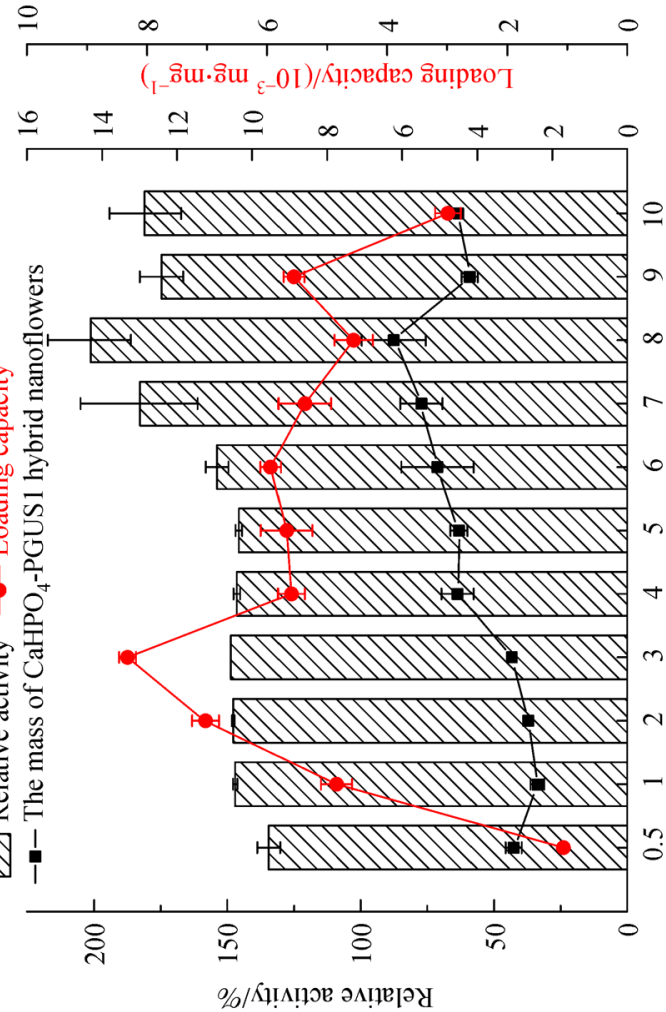

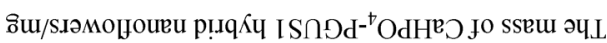
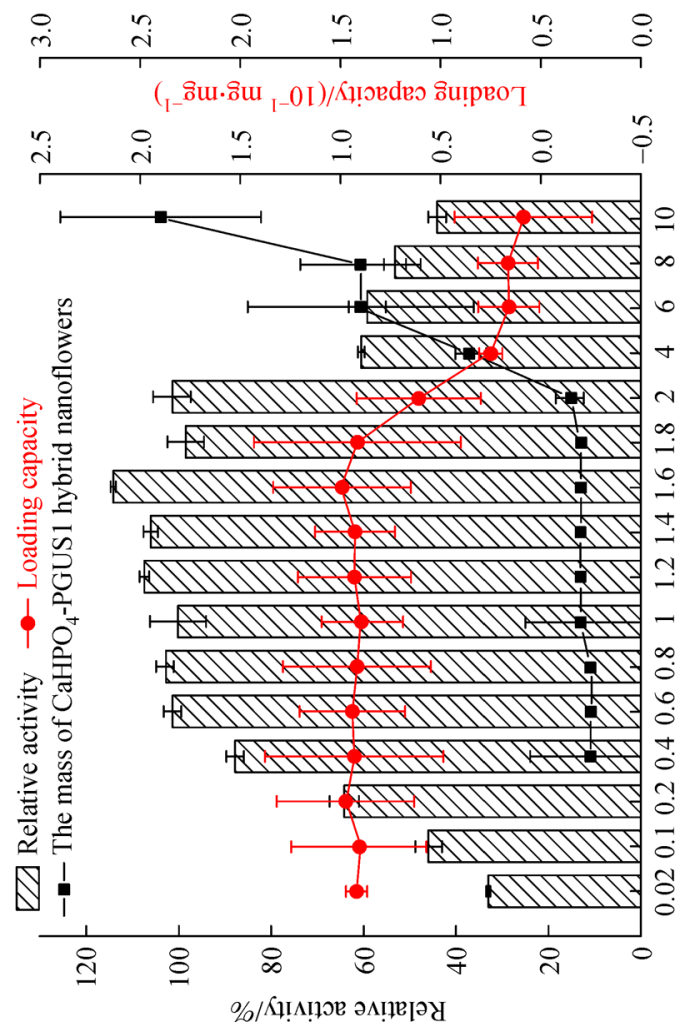

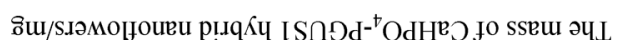
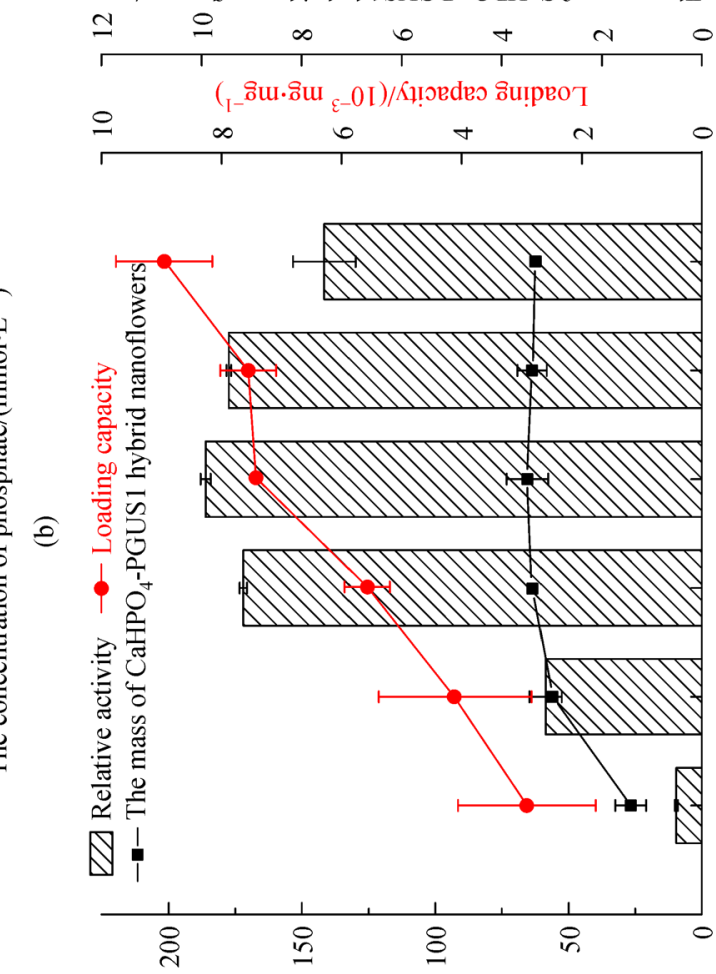

e

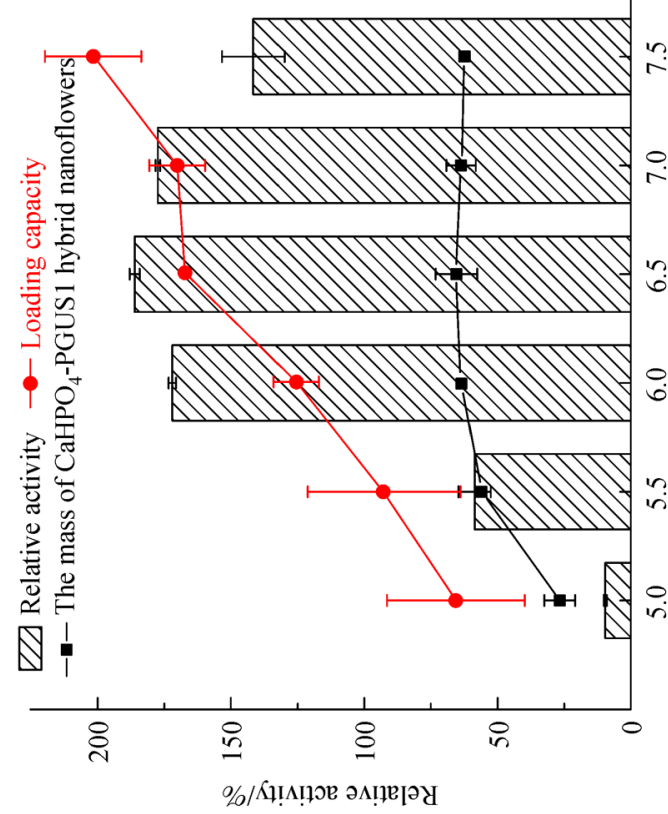

吉 
concentration of $\mathrm{Ca}^{2+}$ was $>2 \mathrm{mmol} \cdot \mathrm{L}^{-1}$, loading capacity and relative activity decreased, while the mass of the $\mathrm{CaHPO}_{4}$-PGUS1 hybrid nanoflower dramatically increased, indicating that the precipitate was mainly in the form of $\mathrm{CaHPO}_{4}$, which is unfavorable for the formation of the $\mathrm{CaHPO}_{4}$-PGUS1 hybrid nanoflower. Higher concentrations of metal ions reportedly increase the thickness of $\mathrm{CaHPO}_{4}$-PGUS1 hybrid nanoflowers, increasing the mass transfer resistance between the substrate and encapsulated enzyme, hence, decreasing enzyme activity [22].

As shown in Fig. 2(b), the mass and relative activity of $\mathrm{CaHPO}_{4}$-PGUS1 hybrid nanoflower were enhanced as the phosphate concentration increased, reaching the highest level at $8 \mathrm{mmol} \cdot \mathrm{L}^{-1}$ of phosphate, and then decreasing thereafter. However, the loading capacity was the highest at $3 \mathrm{mmol} \cdot \mathrm{L}^{-1}$ of phosphate, which may be because the phosphate concentration affected the morphology of the hybrid nanostructures. Wang et al. found that inorganic salt concentrations $<10 \mathrm{mmol} \cdot \mathrm{L}^{-1}$ were favorable for the formation of nanoflowers, and phosphate concentrations $>15 \mathrm{mmol} \cdot \mathrm{L}^{-1}$ were favorable for the formation of nanoplates [18]. Their results also showed that the nanoflowers yielded higher activity than the nanoplates, owing to their higher surface to volume ratio and better hierarchical structure, associated with low probability for assembly.

As shown in Fig. 2(c), precipitate mass and relative activity increased as enzyme concentration increased, until the enzyme concentration reached $0.4 \mathrm{mg} \cdot \mathrm{mL}^{-1}$. At enzyme concentrations $<0.4 \mathrm{mg} \cdot \mathrm{mL}^{-1}$, there were too few proteins to form enough primary nanoparticles, and the nanostructures were mainly in the form of broken petallike aggregates, owing to the inability of low driving forces to assemble the nanoflowers [19]. When the enzyme concentration were $>0.4 \mathrm{mg} \cdot \mathrm{mL}^{-1}$, precipitate mass, loading capacity, and relative activity fluctuated, indicating enzyme saturation. Hence, the optimal enzyme concentration was $0.4 \mathrm{mg} \cdot \mathrm{mL}^{-1}$. Reportedly, medium protein concentrations boost nanoflower formation, and higher protein concentrations result in the formation of nanoflowers with buds, due to the presence of excess $\mathrm{CaHPO}_{4}$ particles during the nucleation period [23]. In this study, the dramatic increase of the mass of the $\mathrm{CaHPO}_{4}-\mathrm{PGUS} 1$ hybrid nanoflower at enzyme concentrations of $0.8^{-}$ $1.0 \mathrm{mg} \cdot \mathrm{mL}^{-1}$ may be attributed to the nanoflower buds, which is unfavorable to enzyme immobilization.

In investigating the effect of $\mathrm{pH}$ 5.0-7.5, we found that the loading capacity increased as the $\mathrm{pH}$ increased (Fig. 2(d)). Relative activity was highest $(186.58 \%)$ at $\mathrm{pH} 6.5$, but decreased as the $\mathrm{pH}$ further increased. This may be because as PGUS1 is an acidic enzyme, it was deactivated as the $\mathrm{pH}$ became more alkaline.

As shown in Fig. 3(a), the precipitate mass increased as the incubation temperature increased, and the maximal mass of $\sim 3 \mathrm{mg}$ was obtained at $40^{\circ} \mathrm{C}$ after $8 \mathrm{~h}$. The mass

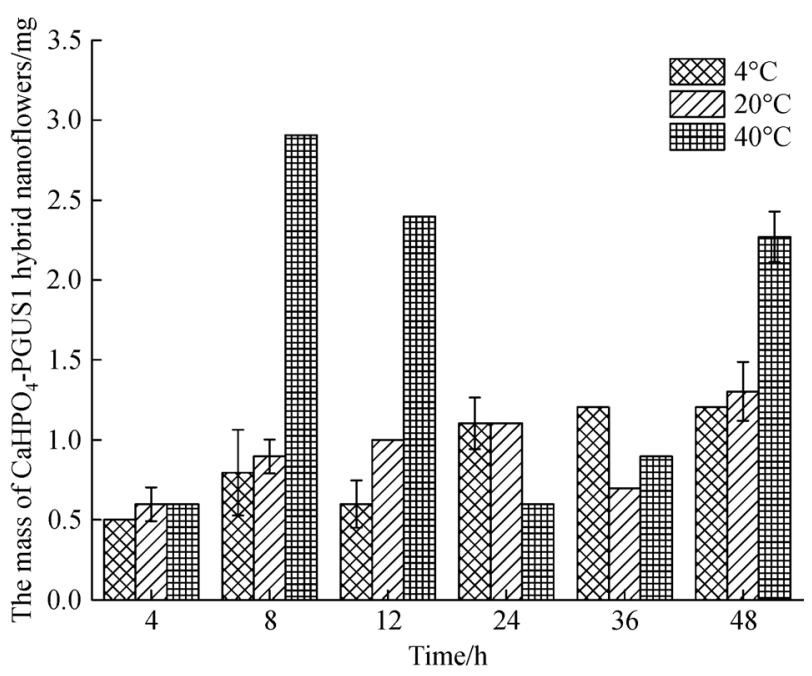

(a)

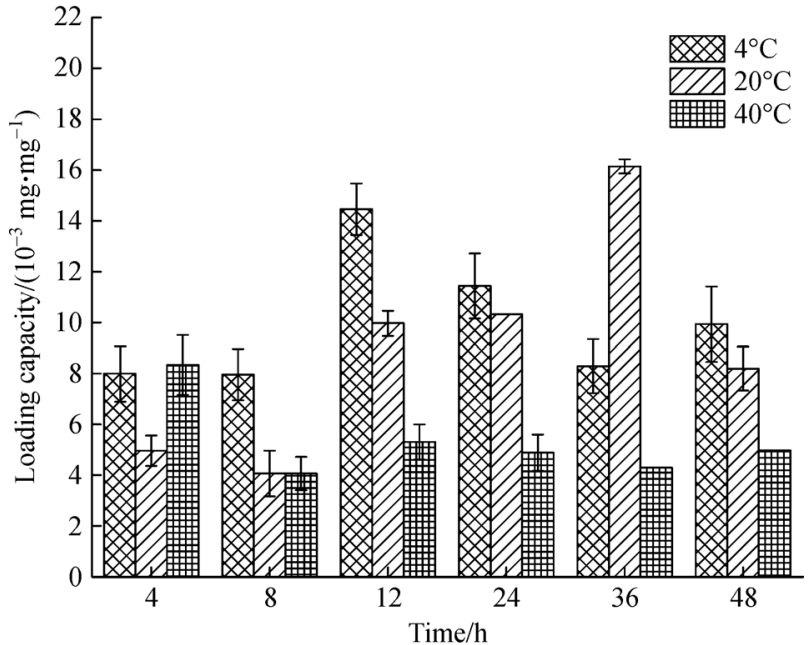

(b)

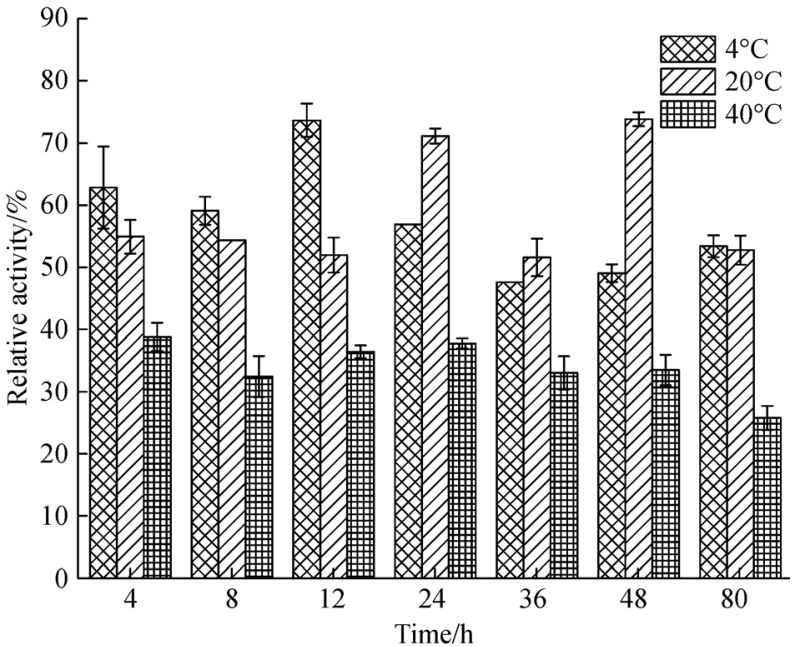

(c)

Fig. 3 Effect of incubation time and temperature on $\mathrm{CaHPO}_{4}$ PGUS1 hybrid nanoflower formation: (a) mass, (b) loading capacity, (c) relative activity. 
Table 1 Optimal conditions for $\mathrm{CaHPO}_{4}$-PGUS1 hybrid nanoflower preparation

\begin{tabular}{lccccc}
\hline $\mathrm{Ca}^{2+} /\left(\mathrm{mmol} \cdot \mathrm{L}^{-1}\right)$ & Phosphate $/\left(\mathrm{mmol} \cdot \mathrm{L}^{-1}\right)$ & $\mathrm{PGUS1} /\left(\mathrm{mg} \cdot \mathrm{mL}^{-1}\right)$ & $\mathrm{pH}$ & Time/h & Temperature $/{ }^{\circ} \mathrm{C}$ \\
\hline 1.6 & 8 & 0.4 & 6.5 & 12 & 4 \\
\hline
\end{tabular}

Table 2 Critical parameters of $\mathrm{CaHPO}_{4}$-PGUS1 hybrid nanoflower prepared under optimal conditions

\begin{tabular}{lccc}
\hline Amount of nanoflowers $/ \mathrm{mg}$ & Immobilization efficiency $/ \%$ & Loading capacity $/\left(\mathrm{mg} \cdot \mathrm{g}^{-1}\right)$ & Relative activity $/ \%$ \\
\hline 1.2 & 71.2 & 35.60 & 118 \\
\hline
\end{tabular}

was only $0.8 \mathrm{mg}$ at $4{ }^{\circ} \mathrm{C}$ and $0.9 \mathrm{mg}$ at $20^{\circ} \mathrm{C}$. However, enzyme loading capacity and relative activity were lowest at $40^{\circ} \mathrm{C}$ (Figs. 3(b,c)), which may be because the high temperature prompted molecular diffusion and too many $\mathrm{CaHPO}_{4}$ particles were formed during the initial period of nucleation, which were unfavorable to enzyme activity in $\mathrm{CaHPO}_{4}$-PGUS1 hybrid nanoflower formation. In addition, due to thermal inactivation, high temperatures may result to partial enzyme activity loss. Therefore, temperatures $<20^{\circ} \mathrm{C}$ favor the formation of $\mathrm{CaHPO}_{4}-\mathrm{PGUS} 1$ hybrid nanoflower. Moreover, the highest relative activity was achieved at 12 and $24 \mathrm{~h}$ during incubation at $4{ }^{\circ} \mathrm{C}$ and $20^{\circ} \mathrm{C}$, respectively. The 3 widely accepted stages for nanoflower formation include: (1) Proteins form complexes with divalent ions through their amine groups, which provide a nucleation site for the formation of primary inorganic nanoparticles; (2) Proteins form petals by linking inorganic nanoparticles; and (3) Petals are assembled to form nanoflowers [24]. The nanoflower formation time of different hybrid systems is significantly different. For example, it reportedly takes $72 \mathrm{~h}$ to form the horseradish peroxidase- $\mathrm{Cu}_{3}\left(\mathrm{PO}_{4}\right)_{2}$ and bovine serum albumin- $\mathrm{Cu}_{3}\left(\mathrm{PO}_{4}\right)_{2}$ nanoflowers [25].

A summary of the optimal conditions for $\mathrm{CaHPO}_{4}$ PGUS1 hybrid nanoflower preparation is shown in Table 1. Under these conditions, $1.2 \mathrm{mg}$ of precipitate was obtained in $1 \mathrm{~mL}$ of reactant with immobilization efficiency of $71.2 \%$, loading capacity of $35.60 \mathrm{mg} \cdot \mathrm{g}^{-1}$, and relative activity of $118 \%$ (Table 2 ). The high relative activity was due to the high surface to volume ratio owed to the highly hierarchy plated structure of the $\mathrm{CaHPO}_{4}$-PGUS1 hybrid nanoflower. The incorporation of $\mathrm{Ca}^{2+}$ was also beneficial to enzyme activity (Fig. 1).

3.3 Characterization of the $\mathrm{CaHPO}_{4}$-PGUS1 hybrid nanoflower

SEM was employed to observe the morphology of the $\mathrm{CaHPO}_{4}$-PGUS1 hybrid nanoflower prepared under optimal conditions. As shown in Figs. 4(a, b), the diameter of the $\mathrm{CaHPO}_{4}$-PGUS1 hybrid nanoflower composed of several nanoplates was approximately $3 \mu \mathrm{m}$, similar to the previously reported diameter of the HRP-embedded hybrid $\mathrm{Cu}_{3}\left(\mathrm{PO}_{4}\right)_{2} \cdot 3 \mathrm{H}_{2} \mathrm{O}$ nanoflower [25]. To verify enzyme encapsulation in the $\mathrm{CaHPO}_{4}$-PGUS1 hybrid nanoflower, FITC-labeled PGUS1 was used to prepare (a)

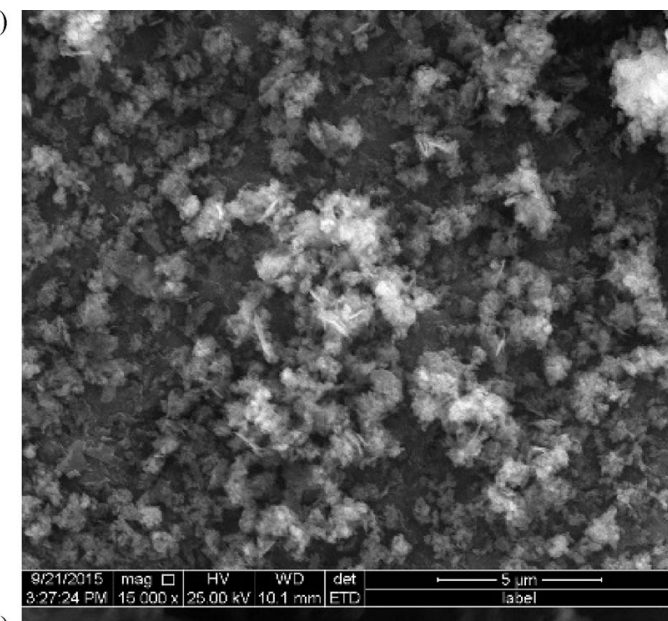

(b)

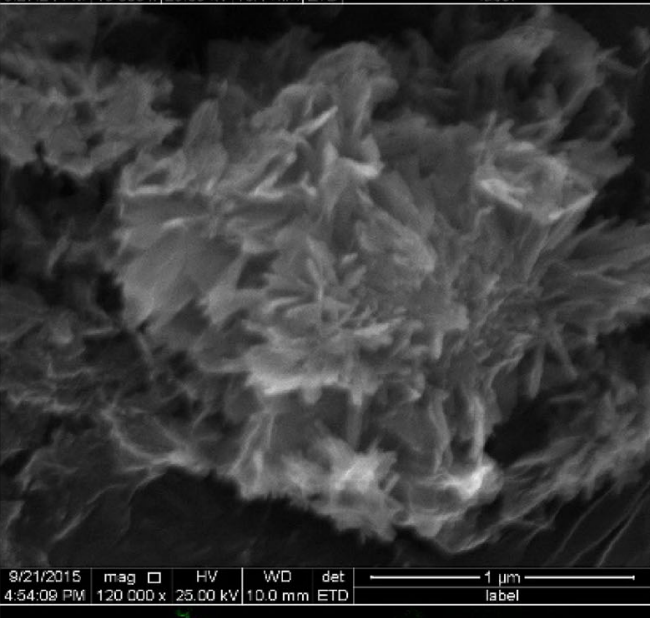

(c)

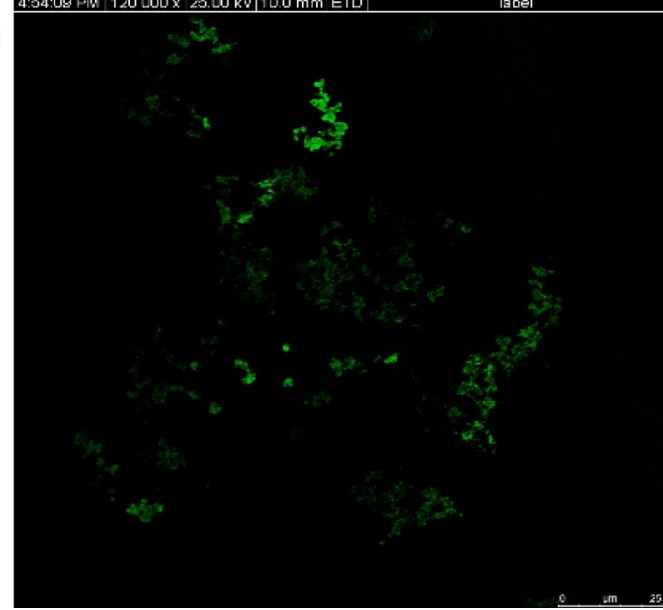

Fig. 4 Characterization of $\mathrm{CaHPO}_{4}-\mathrm{PGUS} 1$ hybrid nanoflower: (a, b) SEM images, (c) CLSM image. 
the hybrid nanoflower, and CLSM was used to characterize it (Fig. 4(c)). We confirmed the absence of fluorescent signals of PGUS1-free precipitates; hence, all signals were owed to PGUS1 precipitates. Fluorescence signals were observed for the $\mathrm{CaHPO}_{4}$-PGUS1 hybrid nanoflowers containing FITC-labeled PGUS1, indicating the involvement of the enzyme in precipitate formation.

As shown in Table 3, the zeta potential of $\mathrm{CaHPO}_{4}$ was $-19.1 \mathrm{mV}$, but increased to $-10.8 \mathrm{mV}$ after the introduction of PGUS1. This may be caused by the charge of the enzyme. In addition, conductivity decreased from 4.9-1.0 $\mathrm{mS} \cdot \mathrm{cm}^{-1}$ after the introduction of PGUS1, because most of the free ions in the solution were involved in nanoflower formation, thus, decreasing the amount left for conductivity. In the absence of the enzyme, no regular nanoparticles were formed, as the sizes of those formed could not be determined since their values exceeded the measuring range. In the presence of PGUS1, the particle sizes of the $\mathrm{CaHPO}_{4}$-PGUS1 hybrid nanoflower were approximately $3.6 \mu \mathrm{m}$, consistent with the SEM results. The particle sizes of the $\mathrm{CaHPO}_{4}$-PGUS1 hybrid nanoflower were between 3-5 $\mu \mathrm{m}$, similar to those previously reported [26,27]. When the particle size is small, the nanoflower structure cannot be formed, and when it is too large, the formed nanoflower structure is unstable. Although $\mathrm{CaHPO}_{4}$ crystal formation could occur without PGUS1 participation, it cannot be automatically assembled to form $\mathrm{CaHPO}_{4}$-PGUS1 hybrid nanoflowers in the absence of PGUS1 as glue.

As shown in Table 4, the $K_{\mathrm{m}}$ value of the $\mathrm{CaHPO}_{4}$ PGUS1 hybrid nanoflower decreased by $41 \%$ compared with that of the free enzyme, illustrating the hybrid nanoflower had a higher affinity to GL. However, the $k_{\text {cat }} / K_{\mathrm{m}}$ value of the $\mathrm{CaHPO}_{4}$-PGUS1 hybrid nanoflower decreased by $46 \%$, because enzyme activity was completely restricted by immobilization, decreasing the flexibility of the enzyme within the nanoflower.

The thermostability of the $\mathrm{CaHPO}_{4}$-PGUS1 hybrid nanoflower at $55^{\circ} \mathrm{C}$ was investigated. The residual activity after treatment at $55^{\circ} \mathrm{C}$ was tested using a GL hydrolysis assay. As shown in Fig. 5(a), free PGUS1 lost most of its activity, with $<25 \%$ of its residual activity left after $10 \mathrm{~h}$. The $\mathrm{CaHPO}_{4}$-PGUS1 hybrid nanoflower showed improved thermostability, and maintained approximately
$50 \%$ of its residual activity after $10 \mathrm{~h}$, indicating it can improve enzyme thermostability. The semi-log plot of residual activity showed a good linear relation with incubation time at $55^{\circ} \mathrm{C}$ (Fig. 5(b)), indicating that the deactivation of both free PGUS1 and $\mathrm{CaHPO}_{4}-\mathrm{PGUS1}$ hybrid nanoflower followed first-order kinetics. The thermal deactivation rate constant of free PGUS1 (0.16 $\mathrm{h}^{-1}$ ) was 1.3 folds higher than that of $\mathrm{CaHPO}_{4}$-PGUS1 hybrid nanoflower $\left(0.07 \mathrm{~h}^{-1}\right)$, because the thermostability of $\mathrm{CaHPO}_{4}$-PGUS1 hybrid nanoflower $\left(t_{1 / 2}\right.$ of $\left.10.2 \mathrm{~h}\right)$ was increased by 1.3 folds compared with that of free PGUS1 $\left(t_{1 / 2}\right.$ of $\left.4.4 \mathrm{~h}\right)$. This may be due to the increased enzyme structure rigidity caused by the interaction between the enzyme and $\mathrm{CaHPO}_{4}$. Previous studies have also elucidated the improved thermostability of immobilized enzymes. For example, immobilization reportedly increased the thermal stability of lipase by 2.4 folds [28].

3.4 Application of the $\mathrm{CaHPO}_{4}$-PGUS1 hybrid nanoflower in GL hydrolysis

The $\mathrm{CaHPO}_{4}$-PGUS1 hybrid nanoflower and free PGUS1 (equal amount of enzyme) were applied in the long-term hydrolysis of GL to GAMG. As shown in Fig. 6(a), during the whole process, the performance of the $\mathrm{CaHPO}_{4}$ PGUS1 hybrid nanoflower was better, and the reaction became stable after $8 \mathrm{~h}$ with $92 \%$ conversion. The reaction proceeded quickly in the first $4 \mathrm{~h}$, and the GL transformation rate was $1.18 \mathrm{mg}(\mathrm{GL}) \cdot \mathrm{g}^{-1}$ (nanoflower) $\cdot \mathrm{h}^{-1}$. However, for the free enzyme, the conversion was only $82 \%$, even after $16 \mathrm{~h}$. This was mainly due to the advantages of the $\mathrm{CaHPO}_{4}$-PGUS1 hybrid nanoflower such as high surface area, which is beneficial to mass transfer.

The $\mathrm{CaHPO}_{4}$-PGUS1 hybrid nanoflower also exhibited good reusability with $60 \%$ residual activity left after 8 consecutive runs (each run was $16 \mathrm{~h}$ ) (Fig. 6(b)). Moreover, deactivation and leakage of the enzyme were also responsible for the activity loss. Centrifugation during the recycling of the $\mathrm{CaHPO}_{4}$-PGUS1 hybrid nanoflower after each run caused leakage of the enzyme from the nanoflower. For future studies, a continuous process should be designed to alleviate enzyme leakage. The reusability of the $\mathrm{CaHPO}_{4}$-PGUS1 hybrid nanoflower was better than those of previously immobilized $\beta$-glucuroni-

Table 3 The zeta potential, conductivity and particle size of $\mathrm{CaHPO}_{4}-\mathrm{PGUS1}$ hybrid nanoflower

\begin{tabular}{lccr}
\hline & Zeta potential $/ \mathrm{mV}$ & Conductivity $/\left(\mathrm{mS} \cdot \mathrm{cm}^{-1}\right)$ & Particle size $/ \mu \mathrm{m}$ \\
\hline $\mathrm{CaHPO}_{4}$ & $-19.1 \pm 3.2$ & $4.9 \pm 0.4$ & $\mathrm{Nd}^{\mathrm{a}}$ \\
Nanoflower & $-10.8 \pm 0.3$ & $1.0 \pm 0.04$ & $3.6 \pm 0.4$ \\
\hline
\end{tabular}

a) Not determined

Table 4 Kinetic parameters of free PGUS1 and $\mathrm{CaHPO}_{4}$-PGUS1 hybrid nanoflower

\begin{tabular}{lccr}
\hline Enzyme & $K_{\mathrm{m}} /\left(\mathrm{mmol} \cdot \mathrm{L}^{-1}\right)$ & $k_{\mathrm{cat}} / \mathrm{s}^{-1}$ & $k_{\mathrm{cat}} / K_{\mathrm{m}}\left(\mathrm{L} \cdot \mathrm{mmol}^{-1} \cdot \mathrm{s}^{-1}\right)$ \\
\hline Free PGUS1 & $2.51 \pm 0.05$ & $5.67 \pm 0.05$ & 2.26 \\
Nanoflower & $1.47 \pm 0.02$ & $1.65 \pm 0.02$ & 1.22 \\
\hline
\end{tabular}




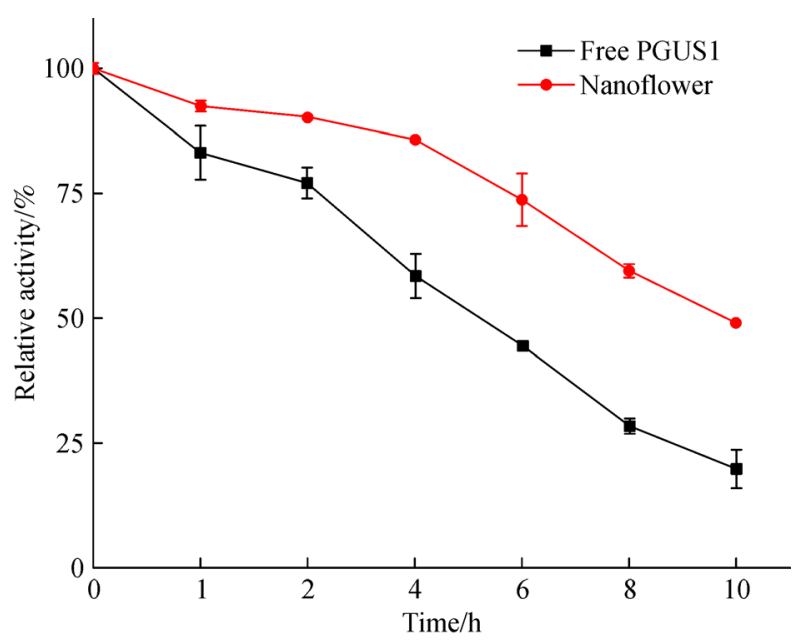

(a)

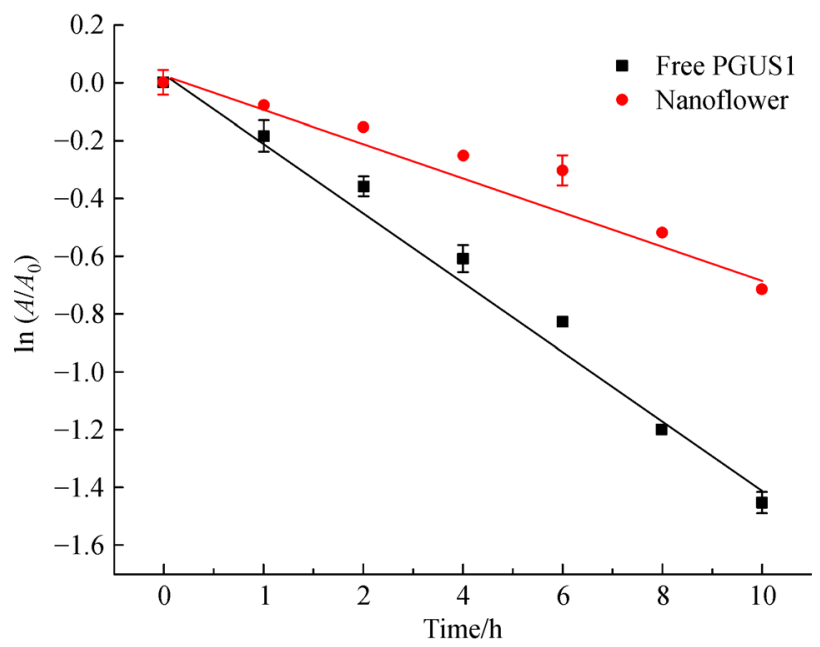

(b)

Fig. 5 (a) Thermostability and (b) thermal deactivation of $\mathrm{CaHPO}_{4}$-PGUS1 hybrid nanoflower and free PGUS1 at $55^{\circ} \mathrm{C}$ in $10 \mathrm{~h}$. Values are the average of 3 independent experiments and error bars represent average \pm 1 S.D.

dase. For example, Wei et al. fabricated a bifunctional graphene $/ \gamma-\mathrm{Fe}_{2} \mathrm{O}_{3}$ hybrid aerogels for $\beta$-glucuronidase immobilization, whose retained activity was decreased to $34.8 \%$ after 7 runs [29]. More recently, Kaleem et al. immobilized $\beta$-glucuronidase on $\mathrm{ZnO}$ nanoparticels, and the retained activity was less than $40 \%$ after 7 runs [30]. Therefore, the potential for the industrial application of the hybrid nanoflowers is high, owing to their stability and reusability.

\section{Conclusions}

The protein-inorganic hybrid self-assembly was first used to synthesize a $\mathrm{CaHPO}_{4}-\mathrm{PGUS} 1$ hybrid nanoflower, whose microstructure was characterized using CLSM, SEM, and

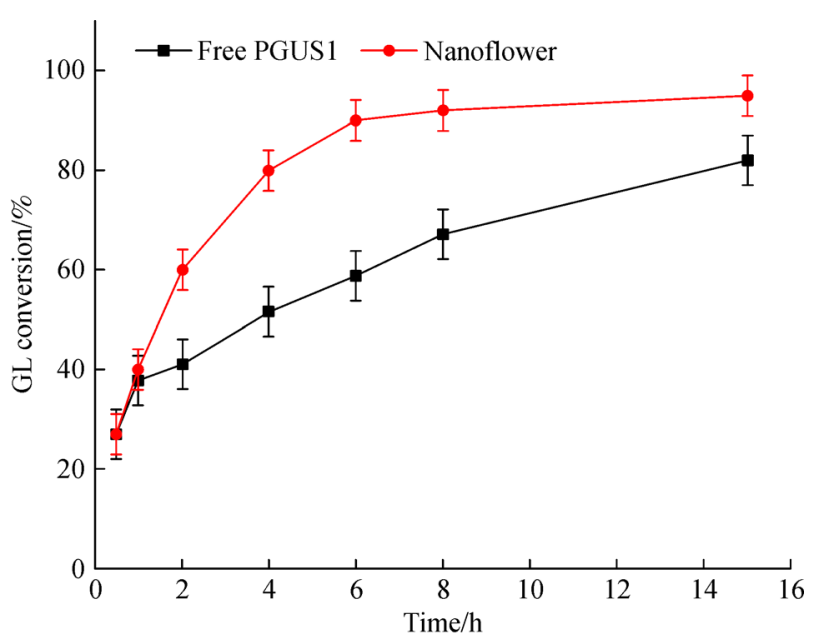

(a)

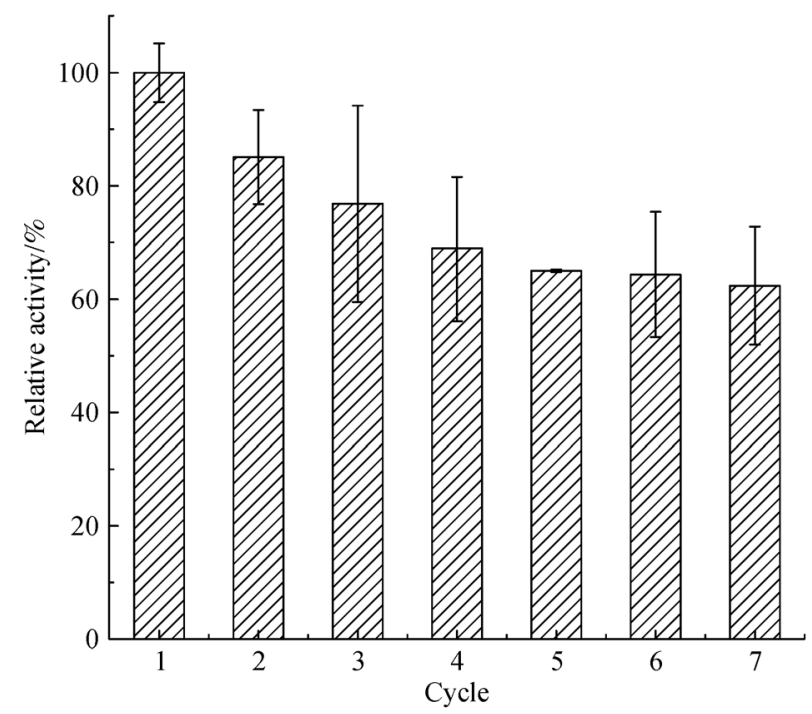

(b)

Fig. 6 The application of $\mathrm{CaHPO}_{4}$-PGUS1 hybrid nanoflower in GL transformation: (a) Course of the biotransformation of GL mediated by free PGUS1 and $\mathrm{CaHPO}_{4}$-PGUS1 hybrid nanoflower $\left(\mathrm{CaHPO}_{4}\right.$-PGUS1 hybrid nanoflower precipitate $(170 \mathrm{mg})$ and equal amount of free enzyme was used); (b) Reusability of $\mathrm{CaHPO}_{4}$-PGUS1 hybrid nanoflower.

FTIR. After optimization, a $1.2 \mathrm{mg}$ precipitate with immobilization efficiency of $71.2 \%$, enzyme loading of $35.60 \mathrm{mg} \cdot \mathrm{g}^{-1}$, and relative activity of $118 \%$ was obtained. The $\mathrm{CaHPO}_{4}$-PGUS1 hybrid nanoflower increased the thermostability of PGUS1. Additionally, the $\mathrm{CaHPO}_{4}$ PGUS1 hybrid nanoflower was used for the preparation of GAMG through GL hydrolysis, with a conversion rate of $92 \%$ in $8 \mathrm{~h}$. The nanoflower showed good reusability, maintaining $60 \%$ of its activity after 8 consecutive runs.

Acknowledgements This research was funded by the National Natural Science Foundation of China (Grant Nos. 21425624, 21878021, and 21506011). 


\section{References}

1. Asl M N, Hosseinzadeh H. Review of pharmacological effects of Glycyrrhiza sp. and its bioactive compounds. Phytotherapy Research, 2010, 22(6): 709-724

2. Cinatl J, Morgenstern B, Bauer G, Chandra P, Rabenau H, Doerr H W. Glycyrrhizin, an active component of liquorice roots, and replication of SARS-associated coronavirus. Lancet, 2003, 361 (9374): 2045-2046

3. Baltina L A. Chemical modification of glycyrrhizic acid as a route to new bioactive compounds for medicine. Current Medicinal Chemistry, 2003, 10(2): 155-171

4. Zhao Y, Lv B, Feng X D, Li C. Perspective on biotransformation and de novo biosynthesis of licorice constituents. Journal of Agricultural and Food Chemistry, 2017, 65(51): 11147-11156

5. Amin H A S, El-Menoufy H A, El-Mehalawy A A, Mostafa E S. Biosynthesis of glycyrrhetinic acid 3- $O$-mono- $\beta$-D-glucuronide by free and immobilized Aspergillus terreus $\beta$-D-glucuronidase. Journal of Molecular Catalysis B: Enzymatic, 2011, 69: 54-59

6. Lu D Q, Li H, Dai Y, Ouyang P K. Biocatalytic properties of a novel crude glycyrrhizin hydrolase from the liver of the domestic duck. Journal of Molecular Catalysis B: Enzymatic, 2006, 43: 148-152

7. Kim D H, Lee S W, Han M J. Biotransformation of glycyrrhizin to $18 \beta$-glycyrrhetinic acid-3-O- $\beta$-D-glucuronide by Streptococcus LJ22, a human intestinal bacterium. Biological \& Pharmaceutical Bulletin, 1999, 22: 320-322

8. Wang X, Liu Y Q, Wang C X, Feng X D, Li C. Properties and structures of $\beta$-glucuronidases with different transformation types of glycyrrhizin. RSC Advances, 2015, 5(84): 68345-68350

9. Lv B, Sun H, Huang S, Feng X, Jiang T, Li C. Structure-guided engineering of the substrate specificity of a fungal $\beta$-glucuronidase toward triterpenoid saponins. Journal of Biological Chemistry, 2018, 293(2): 433-443

10. Han B, Hou Y, Jiang T, Lv B, Zhao L, Feng X, Li C. Computationaided rational deletion of $C$-terminal region improved the stability, activity and expression level of $\mathrm{GH}_{2} \beta$-glucuronidase. Journal of Agricultural and Food Chemistry, 2018, 66(43): 11380-11389

11. Guzik U, Hupert-Kocurek K, Wojcieszyåska D. Immobilization as a strategy for improving enzyme properties-application to oxidoreductases. Molecules (Basel, Switzerland), 2014, 19(7): 8995-9018

12. Hou C, Wang Y, Zhu H, Wei H. Construction of enzyme immobilization system through metal-polyphenol assisted $\mathrm{Fe}_{3} \mathrm{O}_{4} /$ chitosan hybrid microcapsules. Chemical Engineering Journal, 2016, 283: 397-403

13. Song X, Jiang Z, Li L, Wu H. Immobilization of $\beta$-glucuronidase in lysozyme-induced biosilica particles to improve its stability. Frontiers of Chemical Science and Engineering, 2014, 8(3): 353361

14. Jesionowski T, Zdarta J, Krajewska B. Enzyme immobilization by adsorption: A review. Adsorption, 2014, 20(5-6): 801-821

15. Yang X Y, Guo Y S, Zhang S S. Ultrasensitive enhanced chemiluminescence enzyme immunoassay for the determination of alpha-fetoprotein amplified by double-codified gold nanoparticles labels. Biosensors \& Bioelectronics, 2009, 24(8): 2707-2711

16. Ge J, Lei J, Zare R N. Protein-inorganic hybrid nanoflowers. Nature Nanotechnology, 2012, 7(7): 428-432

17. Wu Z, Li X, Li F, Yue H, He C, Wang Z. Enantioselective transesterification of $(\mathrm{R}, \mathrm{S})-2$-pentanol catalyzed by a new flowerlike nanobioreactor. RSC Advances, 2014, 4(64): 33998-34002

18. Wang L B, Wang Y C, He R, Zhuang A, Wang X, Zeng J, Hou J G. A new nanobiocatalytic system based on allosteric effect with dramatically enhanced enzymatic performance. Journal of the American Chemical Society, 2013, 135(4): 1272-1275

19. Lin Z, Xiao Y, Yin Y, Hu W, Liu W, Yang H. Facile synthesis of enzyme-inorganic hybrid nanoflowers and its application as a colorimetric platform for visual detection of hydrogen peroxide and phenol. ACS Applied Materials \& Interfaces, 2014, 6(13): 1077510782

20. Bradford M M. Rapid and sensitive method for quantitation of microgram quantities of protein utilizing principle of protein-dye binding. Analytical Biochemistry, 1976, 72(1-2): 248-254

21. Henley J P, Sadana A. Deactivation theory. Biotechnology and Bioengineering, 1986, 28(8): 1277-1285

22. Duan Y, Liu X, Han L, Asahina S, Xu D, Cao Y, Yao Y, Che S. Optically active chiral $\mathrm{CuO}$ "nanoflowers". Journal of the American Chemical Society, 2014, 136(20): 7193-7196

23. Zeng J, Xia Y. Hybrid nanomaterials. Not just a pretty flower. Nature Nanotechnology, 2012, 7(7): 415-416

24. Sun J, Ge J, Liu W, Lan M, Zhang H, Wang P, Wang Y, Niu Z. Multi-enzyme co-embedded organic-inorganic hybrid nanoflowers: Synthesis and application as a colorimetric sensor. Nanoscale, 2014, 6(1): 255-262

25. Lin Z, Xiao Y, Wang L, Yin Y, Zheng J, Yang H, Chen G. Facile synthesis of enzyme-inorganic hybrid nanoflowers and their application as an immobilized trypsin reactor for highly efficient protein digestion. RSC Advances, 2014, 4(27): 13888-13891

26. Chen S, Shi X, Osaka A, Gao H, Hanagata N. Facile synthesis, microstructure and BMP-2 delivery of novel silica hollow flowers for enhanced osteoblast differentiation. Chemical Engineering Journal, 2014, 246: 1-9

27. Wang X, Shi J, Li Z, Zhang S, Wu H, Jiang Z, Yang C, Tian C. Facile one-pot preparation of chitosan/calcium pyrophosphate hybrid microflowers. ACS Applied Materials \& Interfaces, 2014, 6: $14522-14532$

28. Feng X, Patterson D, Balaban M, Emanuelssom E. Characterization of tributyrin hydrolysis by immobilized lipase on woolen cloth using conventional batch and novel spinning cloth disc reactors. Chemical Engineering Research \& Design, 2013, 91(9): 1684-1692

29. Chen L, Wei B, Zhang X, Li C. Bifunctional graphene $/ \gamma-\mathrm{Fe}_{2} \mathrm{O}_{3}$ hybrid aerogels with double nanocrystalline networks for enzyme immobilization. Small, 2013, 9(13): 2331-2340

30. Kaleem I, Rasool A, Lv B, Riaz N, Hassan J U, Manzoor R, Li C. Immobilization of purified $\beta$-glucuronidase on $\mathrm{ZnO}$ nanoparticles for efficient biotransformation of glycyrrhizin in ionic liquid/buffer biphasic system. Chemical Engineering Science, 2017, 162: 332340 